Academic Platform Journal of Engineering and Science

journal homepage: $\underline{\text { http://apjes.com/ }}$

\title{
Theoretical Investigation on Static Analysis of Pultruded GFRP Composite Beams
}

\author{
${ }^{1}$ Emrah Madenci, ${ }^{2}$ Yasin Onuralp Özkılıç *32okman Gemi \\ ${ }^{1}$ Faculty of Engineering and Architecture, Department of Civil Engineering, Necmettin Erbakan University, Konya, Turkey, \\ emadenci@erbakan.edu.tr, (D) \\ ${ }^{2}$ Faculty of Engineering and Architecture, Department of Civil Engineering, Necmettin Erbakan University, Konya, Turkey, \\ yoozkilic@gmail.com, \\ *33eram Vocational School, Necmettin Erbakan University, Konya, Turkey, \\ lgemi@erbakan.edu.tr,
}

Research Paper

Arrival Date: 09.05.2020

Accepted Date: 01.07.2020

\begin{abstract}
Composite materials, which have been used especially in the construction sector to strength beams and columns, have been produced in pultruded GFRP profiles with different geometries with the pultrusion method. Pultruded GFRP profiles are an alternative to traditional building elements in many construction applications thanks to their superior properties such as high strength, chemical resistance, thermal and electrical insulation. Pultruded GFRP profiles are exposed to various loads and change shapes due to the effect of these loads. It is very important to determine the load and deformation capacities as structural members. These profiles are often exposed to bending while serving as beams. In this study, a multiscale analysis of the deflection and stress behavior of pultruded GFRP composite beam is presented. The proposed formulations are verified using the results of experimental and numerical studies. The comparison of the analytical results to both experimental and finite element results revealed that the differences between analytical results and the experimental and numerical findings are less than $1 \%$, which indicates an excellent agreement.
\end{abstract}

Keywords: Pultruded GFRP, Pultrusion, Bending, Experiment, Analytical, Composite, Delamination

\section{INTRODUCTION}

Pultruded composite profiles particularly made of glass fiber reinforced polymer (GFRP) are widely used as critical elements in civil engineering applications due to their superior mechanical strength such as high strength/density ratio, lightness, low density, corrosion resistance and high resistance to chemicals and electrical insulation [1-5].

Besides its superior mechanical performance on the production techniques of these materials, increasing technological developments can also be shown in recent years. The pultrusion method has been developed to produce profile type materials economically. Pultrusion requiring one-way mechanical property is a preferred continuous production method for the production of special materials such as rebar, profile and small diameter pipes [6-8]. It is the fastest improving composite production method, thanks to its economics and usage by many markets [9]. Continuous roving, woven roving, felt or a combination of these, which are used as glass fiber reinforcement in pultrusion, are preferred through thermoset resin bath and then through a series of shaping guides. It is passed through the heated steel mold and it is hardened in the determined section. Forming guides are used to ensure the highest level of penetration of the resin into the glass reinforcement material. The product coming out of the mold is cut to desired lengths by means of cutting apparatus. Pultrusion method requires low labor. Methods of the production of pultruded profile, machine configurations, pultrusion composite diagram and general configuration of structural fibers distributed throughout the thermoset resin are given in Fig. 1.

The static, stability and vibration analyses play a significant role under various types of loading conditions in the design of composite structures. The research and studies on composite structures are divided into two groups as experimental and theoretical in the literature [13-17]. A number of investigations on theoretical or experimental studies of pultruded GFRP composite structures can be found in the literature [18-22]. A comprehensive study was conducted by Madenci et al. [23]. They investigated the flexure performances of pultruded GFRP composite beams with experimentally and theoretically. Theoretical approaches for flexural analysis of pultruded GFRP composite beams were developed with the help of variational 
methods, classical finite element modeling (FEM) was performed with the help of ABAQUS program and threepoint bending test was utilized to investigate flexure performance.

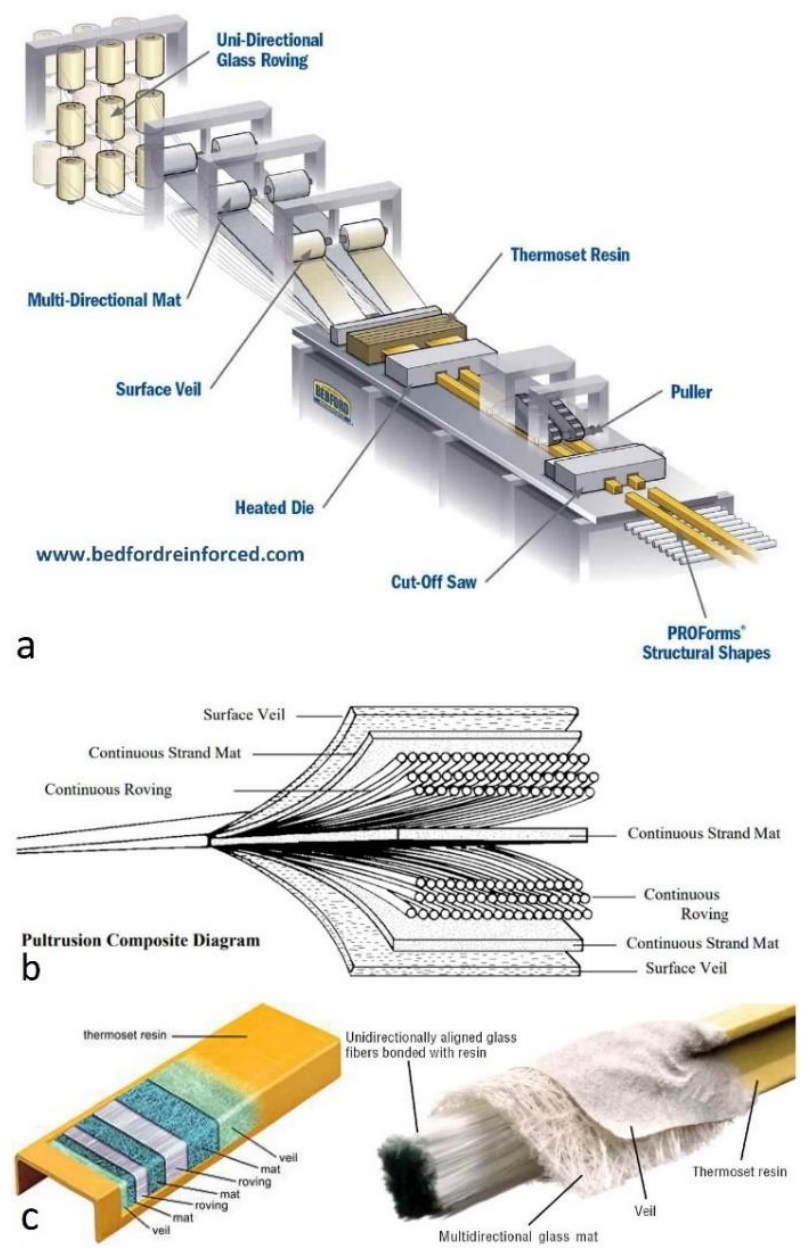

Fig. 1. Pultrusion molding method a) pultrusion machine configurations b) pultrusion composite diagram c) general configuration of structural fibers distributed throughout the thermoset resin [10-12].

The studies related to mechanic behavior analysis of pultruded GFRP composite beams with experimental and theoretical are very limited. This study aims to analyze the behavior of pultruded GFRP composite structures under external loads using a theoretical approach. The deflection and stress behaviors of pultruded GFRP composite beams were examined by using multiscale analysis. The results of the theoretical approach were verified using findings of the experimental study, where the pultruded GFRP beams were tested under three-point bending, and numerical analysis, where finite element modeling using ABAQUS were conducted. In the theoretical analysis section of the [23], field equations were obtained with the help of variational methods and analyzes were carried out with the help of the mixed finite element method, which is a specific approximate solution method. In the theoretical analysis part of this study, an analytical solution was made using simple body equations. In addition, in the study conducted by [23], a macro-mechanical model was used for the material properties, and the results were compared with the results obtained from the experimental analysis. In this study, without any macro-mechanical model for the theoretical solution, the material properties were determined by experimental analysis and used in the theoretical solution.

\section{BASIC EQUATIONS}

The deflection and stress behavior of pultruded GFRP composite beam are summarized according to the classical laminated plate theory in this section. If the in-plane forces and displacements are zero the problem is reduced to one of solving for bending deflection and stresses.

The constitutive relations for laminated beam under bending loads are given by Reddy [24] as

$\left\{\begin{array}{l}M_{x x} \\ M_{x y}\end{array}\right\}=-\left[\begin{array}{ccc}D_{11} & D_{12} & D_{16} \\ D_{12} & D_{22} & D_{26} \\ D_{16} & D_{26} & D_{66}\end{array}\right]\left\{\begin{array}{c}\frac{\partial^{2} w_{0}}{\partial x^{2}} \\ \frac{\partial^{2} w_{0}}{\partial y^{2}} \\ 2 \frac{\partial^{2} w_{0}}{\partial x \partial y}\end{array}\right\}$

We can write Eq. (1) in inverse form as

$$
\left\{\begin{array}{l}
\frac{\partial^{2} w_{0}}{\partial x^{2}} \\
\frac{\partial^{2} w_{0}}{\partial y^{2}} \\
2 \frac{\partial w_{0}}{\partial x \partial y}
\end{array}\right\}=-\left[\begin{array}{lll}
D_{11}^{*} & D_{12}^{*} & D_{16}^{*} \\
D_{12}^{*} & D_{22}^{*} & D_{26}^{*} \\
D_{16}^{*} & D_{26}^{*} & D_{66}^{*}
\end{array}\right]\left\{\begin{array}{l}
M_{x x} \\
M_{y y} \\
M_{x y}
\end{array}\right\}
$$

where " $D_{i j}^{*}$ " the elements of the inverse matrix of " $D_{i j}$ ". In deriving the laminated beam theory we assume that

$M_{y y}=M_{x y}=0$

The differential equation governing the deflection of the beam with along the $\mathrm{x}$-axis can be written as

$\frac{\partial^{2} w_{0}}{\partial x^{2}}=-D_{11}^{*} M_{x x}$

$\frac{\partial^{2} w_{0}}{\partial y^{2}}=-D_{12}^{*} M_{x x}$

$2 \frac{\partial^{2} w_{0}}{\partial x \partial y}=-D_{16}^{*} M_{x x}$ 
where " $D_{i j}^{*}$ " are given by

$$
\begin{aligned}
& D_{11}^{*}=\frac{D_{22} D_{66}-D_{26} D_{26}}{\Delta} \\
& D_{12}^{*}=\frac{D_{16} D_{26}-D_{12} D_{66}}{\Delta} \\
& D_{16}^{*}=\frac{D_{12} D_{26}-D_{22} D_{16}}{\Delta}
\end{aligned}
$$

with " $\Delta$ " being the determinant of the " $\left[D_{i j}\right]$ " matrix can be expressed as

$$
\begin{aligned}
\Delta= & D_{11} D_{22} D_{66}+2 D_{12} D_{16} D_{26}-D_{11} D_{26} D_{26} \\
& -D_{22} D_{16} D_{16}-D_{66} D_{12} D_{12}
\end{aligned}
$$

In Eqs. (4) indicate that the transverse deflection " $w_{0}$ " isn't independent of the $y$-axis while the Poisson effect " $D_{12}^{*}$ " and anisotropic shear coupling " $D_{16}^{*}$ " independent of the y-axis. These effects can be neglected only when the length-towidth ratio of beam is large. We assume that the laminated beam under consideration is long enough to make the effects of the Poisson ratio " $D_{12}^{*}$ " and shear coupling " $D_{16}^{*}$ " on the deflection negligible. In the familiar form used in the EulerBernoulli beam theory, the differential Eq.(4a) can be written in terms of the effective Young's modulus " $E_{x x}^{b}$ ", moment of inertia " $I_{y y}$ " defined as

$$
M(x)=-E_{x x}^{b} I_{y y} \frac{\partial^{2} w_{0}}{\partial x^{2}}
$$

For static bending without axial force, the general solutions are obtained by direct integration by [25]

$$
E_{x x}^{b} I_{y y} w_{0}(x)=\int_{0}^{x}\left[\int_{0}^{\eta} M(\xi) d \xi\right] d \eta+b_{1} x+b_{2}
$$

where the constants are evaluated using boundary conditions for simply supported beam and three point bending

$$
w_{0}(0)=0 ; \quad \frac{d w_{0}}{d x}(L / 2)=0
$$

The in-plane stress in the nth layer computed as

$$
\begin{aligned}
& \left\{\begin{array}{l}
\sigma_{x x} \\
\sigma_{y y} \\
\tau_{x y}
\end{array}\right\}=z\left[\begin{array}{lll}
\bar{Q}_{11} & \bar{Q}_{12} & \bar{Q}_{16} \\
\bar{Q}_{12} & \bar{Q}_{22} & \bar{Q}_{26} \\
\bar{Q}_{16} & \bar{Q}_{26} & \bar{Q}_{66}
\end{array}\right]^{(k)}\left\{\begin{array}{c}
-\frac{\partial^{2} w_{0}}{\partial x^{2}} \\
-\frac{\partial^{2} w_{0}}{\partial y^{2}} \\
-2 \frac{\partial^{2} w_{0}}{\partial x \partial y}
\end{array}\right\} \\
& =\frac{z}{b}\left[\begin{array}{lll}
\bar{Q}_{11} & \bar{Q}_{12} & \bar{Q}_{16} \\
\bar{Q}_{12} & \bar{Q}_{22} & \bar{Q}_{26} \\
\bar{Q}_{16} & \bar{Q}_{26} & \bar{Q}_{66}
\end{array}\right]^{(k)}\left[\begin{array}{ccc}
D_{11}^{*} & D_{12}^{*} & D_{16}^{*} \\
D_{12}^{*} & D_{22}^{*} & D_{26}^{*} \\
D_{16}^{*} & D_{26}^{*} & D_{66}^{*}
\end{array}\right]\left\{\begin{array}{c}
M \\
0 \\
0
\end{array}\right\}
\end{aligned}
$$

The components of the matrix in Eq. (10) in terms of the stiffness coefficients in the direction of principal axes of material orthotropy can be written as Eq. (11)

$$
\begin{aligned}
& \bar{Q}_{11}^{(k)}=Q_{11}^{(k)} \mathrm{c}^{4}+2\left(Q_{12}^{(k)}+2 Q_{66}^{(k)}\right) \mathrm{c}^{2} \mathrm{~s}^{2}+Q_{22}^{(k)} \mathrm{s}^{4} \\
& \bar{Q}_{12}^{(k)}=\left(Q_{11}^{(k)}+Q_{22}^{(k)}-4 Q_{66}^{(k)}\right) \mathrm{c}^{2} \mathrm{~s}^{2}+Q_{12}^{(k)}\left(\mathrm{c}^{4}+\mathrm{s}^{4}\right) \\
& \bar{Q}_{22}^{(k)}=Q_{11}^{(k)} \mathrm{s}^{4}+2\left(Q_{12}^{(k)}+2 Q_{66}^{(k)}\right) \mathrm{c}^{2} \mathrm{~s}^{2}+Q_{22}^{(k)} \mathrm{c}^{4} \\
& \bar{Q}_{16}^{(k)}=\left(Q_{11}^{(k)}-Q_{12}^{(k)}-2 Q_{66}^{(k)}\right) \mathrm{c}^{3} \mathrm{~s}+\left(Q_{11}^{(k)}-Q_{22}^{(k)}+2 Q_{66}^{(k)}\right) \mathrm{cs}^{3} \\
& \bar{Q}_{26}^{(k)}=\left(Q_{11}^{(k)}-Q_{12}^{(k)}-2 Q_{66}^{(k)}\right) \mathrm{cs}^{3}+\left(Q_{11}^{(k)}-Q_{22}^{(k)}+2 Q_{66}^{(k)}\right) \mathrm{c}^{3} \mathrm{~s} \\
& \bar{Q}_{66}^{(k)}=\left(Q_{11}^{(k)}+Q_{22}^{(k)}-2 Q_{12}^{(k)}\right) \mathrm{c}^{2} \mathrm{~s}^{2}+Q_{66}^{(k)}\left(\mathrm{c}^{2}-\mathrm{s}^{2}\right)^{2}
\end{aligned}
$$

where "c" is " $\cos \theta$ " and "s" is " $\sin \theta$ " and " $\theta$ " is the angle between material orientation and $\mathrm{x}$-axis. The terms of engineering constants of the $k$ th orthotropic lamina are

$$
\begin{aligned}
& Q_{11}^{(k)}=\frac{E_{1}^{(k)}}{1-v_{12} v_{21}}, \quad Q_{12}^{(k)}=\frac{v_{12} E_{2}^{(k)}}{1-v_{12} v_{21}}, \quad Q_{22}^{(k)}=\frac{E_{2}^{(k)}}{1-v_{12} v_{21}}, \\
& Q_{44}^{(k)}=G_{13}, \quad Q_{55}^{(k)}=G_{23}, \quad Q_{66}^{(k)}=G_{12}
\end{aligned}
$$

The laminate material stiffnesses " $D_{i j}$ " are given based on transformed rigidity

$$
\left\{D_{i j}\right\}=\sum_{k=1}^{N} \int_{z_{k}}^{z_{k+1}}\left[\bar{Q}_{i j}\right]^{(k)} z^{2} d z
$$

\section{EXPERIMENTAL STUDY}

In order to verify theoretical results, the experimental study which was conducted by the Authors [23] was utilized. For the sake of completeness, the details of the experimental study are explained herein. According to burnout test the volume fraction of fiber and matrix were determined as $54 \%$ and $46 \%$, respectively. Interested readers can refer to Madenci et al [23] for more detail. In the experimental study, three different type of specimens were tested under three point loading using SHIMAZDZU universal test machine 
shown in Fig. 2. The specimens were taken from the pultruded GFRP profile. Specimens CB1 and CB2 were taken from longitudinal direction while CB3 specimen was taken from the transverse direction. Dimension and fiber orientation of specimens are given in Table 1.

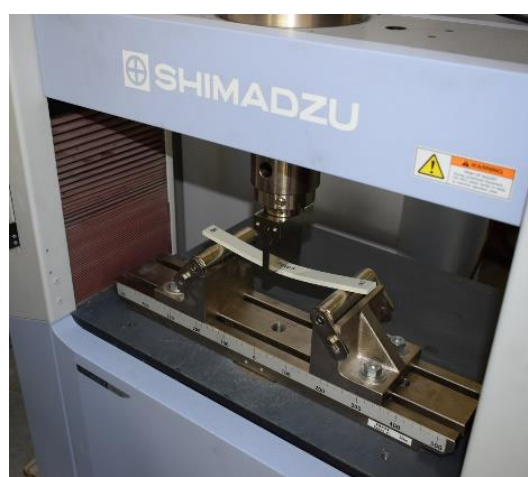

Fig. 2. Test setup

Table 1. Properties of the specimens

\begin{tabular}{lllll}
\hline Specimen & $\begin{array}{l}\text { Fiber } \\
\text { Orientation }\end{array}$ & $\begin{array}{l}\text { Thickness } \\
(\mathrm{mm})\end{array}$ & $\begin{array}{l}\text { Width } \\
(\mathrm{mm})\end{array}$ & $\begin{array}{l}\text { Span } \\
\text { Length }\end{array}$ \\
\hline CB1 & $0^{\circ}$ & 6 & 25 & 190 \\
CB2 & $0^{\circ}$ & 6 & 13 & 96 \\
CB3 & $90^{\circ}$ & 6 & 150 & 100 \\
\hline
\end{tabular}

Tensile tests were performed in order to measure tensile strength and elasticity modulus for longitudinal and transverse directions. Modulus of elasticities were measured as $23 \mathrm{GPa}$ and $7 \mathrm{GPa}$ for longitudinal and transverse directions, respectively. Stress and strain curves of the results of tensile test for the longitudinal and transverse directions are given in Fig. 3. For more details, Özkiliç et al [26] can be referred.

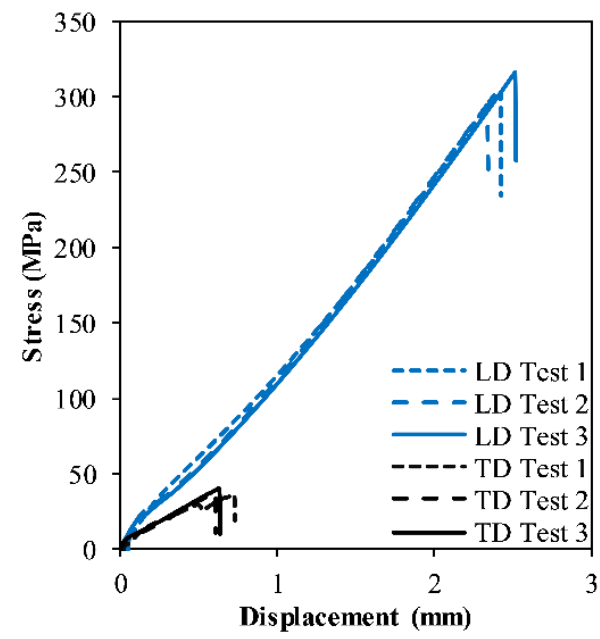

Fig. 3. The tensile test results of longitudinal direction (LD) and transverse direction (TD)

\section{NUMERICAL STUDY}

In the content of the study [23], the numerical study was also conducted to further verify the theoretical formulation. In this present study, the results of numerical study were also included herein. The numerical study was carried out using a commercial finite element (FE) software, ABAQUS. ABAQUS is a powerful and reliable tool used by many researchers to solve civil engineering problems [27]. The specimen was modeled using S4R shell elements. The supports and loading nose were modeled using C3D8R solid elements. Mesh size was determined after the convergence analyses. $5 \mathrm{~mm}$ mesh size was utilized to model the beams. Lamina type of material model was considered for modelling the beams. Elastic modulus of $23 \mathrm{GPa}$ and $7 \mathrm{GPa}$ was used for the longitudinal and transverse directions. Numerical model is shown in Fig. 4. More detail related to numerical model can be found in the study conducted by Madenci et al. [23].

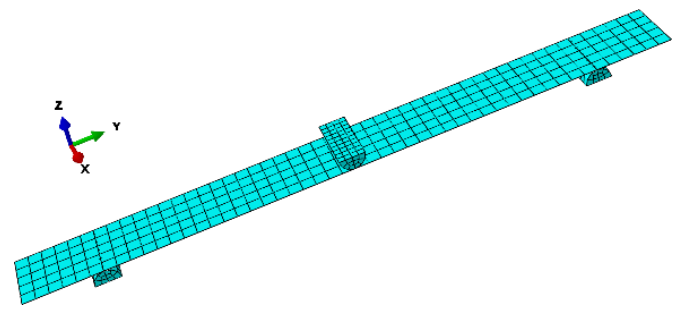

Fig. 4. Numerical model

\section{RESULTS}

In the results, 3 replicates were made for each sample combination. Load and displacement measurements were carried out 3 replicates for each sample and these values are given in Table 2 . The obtained results are compared in terms of maximum displacement and maximum normal stress. Maximum displacements of the specimens are compared in Table 3. It is seen that the results of the analytical and FEM match very closely each other. On the other hand, experimental results are slightly higher than those of the calculated results which are analytical and FEM results. The differences between experimental findings and the calculated results are less than $1 \%$ which indicates an excellent agreement between experimental and the calculated results.

Table 2. Standard deviation (SD) of specimens

\begin{tabular}{ccccc}
\hline Specimen & Load $(\mathrm{N})$ & SD & Disp. (mm) & SD \\
\hline CB1-1 & 945.3045 & & 10.8512 & \\
CB1-2 & 973.4536 & \multirow{2}{*}{13.78} & 11.9744 & 0.64 \\
CB1-3 & 975.5137 & & 12.3642 & \\
\hline CB2-1 & 930.3281 & & 3.5642 & \\
CB2-2 & 942.1822 & \multirow{2}{*}{18.39} & 3.8998 & 0.16 \\
CB2-3 & 973.9020 & & 3.9059 & \\
\hline CB3-1 & 372.5171 & & 2.7421 & \\
CB3-2 & 342.3757 & \multirow{2}{*}{13.39} & 2.1765 & 0.27 \\
CB3-3 & 368.6370 & & 2.7613 & \\
\hline
\end{tabular}

Table 3. Maximum displacements of specimens

\begin{tabular}{cccc}
\hline & \multicolumn{3}{c}{ Maximum displacement $(\mathrm{mm})$} \\
\hline Specimen & Experimentally & Analytical & FEM \\
\hline CB1 & 11.73 & 11.71 & 11.70 \\
CB2 & 3.79 & 3.76 & 3.75 \\
CB3 & 2.56 & 2.45 & 2.46 \\
\hline
\end{tabular}


Table 4 demonstrates maximum normal stress occurred at the specimens. Similar to previous results, herein very close results from analytical and FEM studies are obtained whereas experimental results are slightly lower than the calculated results. Again the difference between experimental findings and the calculated results are less than $1 \%$.

Table 4. Maximum normal stresses of specimens

\begin{tabular}{cccc}
\hline & \multicolumn{3}{c}{ Maximum normal stress (MPa) } \\
\hline Specimen & Experimentally & Analytical & FEM \\
\hline CB1 & 362 & 363 & 363.06 \\
CB2 & 422 & 421.3 & 421.24 \\
CB3 & 68 & 68.5 & 68.42 \\
\hline
\end{tabular}

The values obtained as a result of the analytical solution were very close to each other with the results of the theoretical solution in the study conducted by Madenci et. al. [23]. In the study conducted by the [23], the material properties were obtained by establishing a detailed mechanical model, while the material properties were obtained experimentally in this study. Thus, the results of the analytical solution and the results of the theoretical solution used in the study conducted by the Madenci et. al. [23] came close.

The comparison of the load-displacement curves for CB1, CB2 and CB3 are given in Figs. 5, 6 and 7, respectively. It is seen that, all repeat tests give similar results in terms of maximum loading and corresponding displacement. It can seen from these figures that both analytical and finite element (FE) results can successful predict the elastic region of the pultruded GFRP.

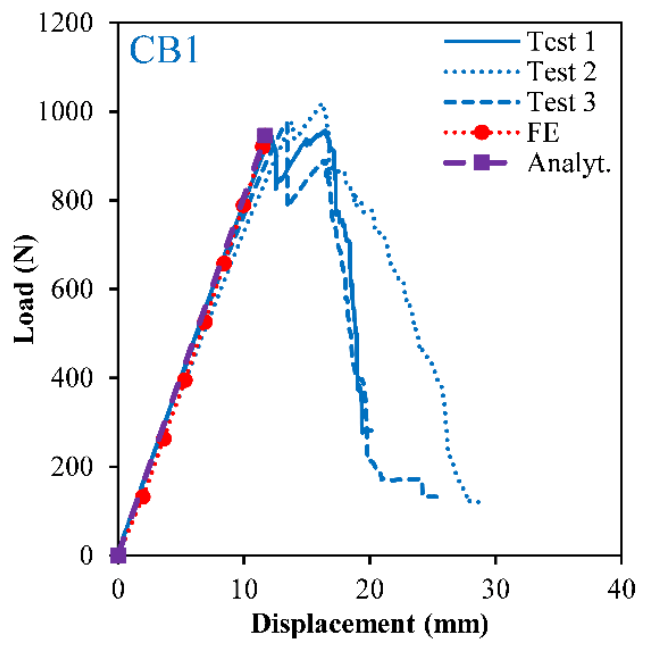

Fig. 5. The comparison of the load-displacement curves for CB1

The composite structures produced in different production methods and geometries are subjected to damage analysis after the experimental study [28-33]. Each type of composite materials has their own unique damages. It is very important to provide feedback through the composite production method stage in order to determine the damage modes and to minimize these losses by developing the production method [34-46].

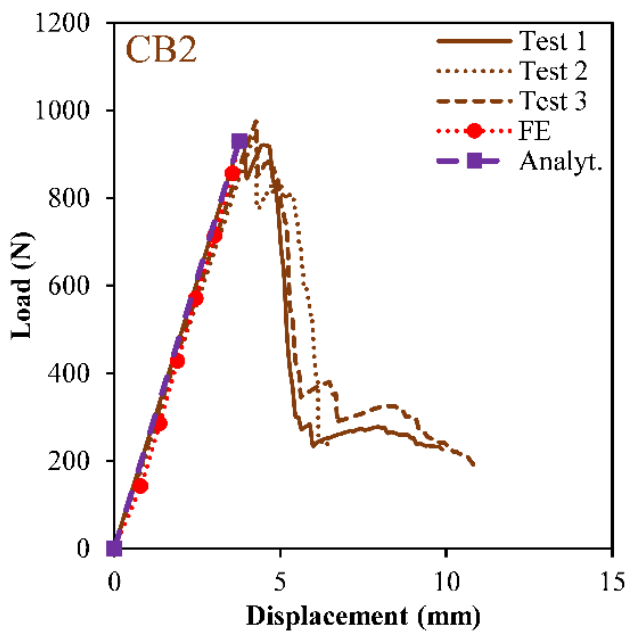

Fig. 6. The comparison of the load-displacement curves for CB2

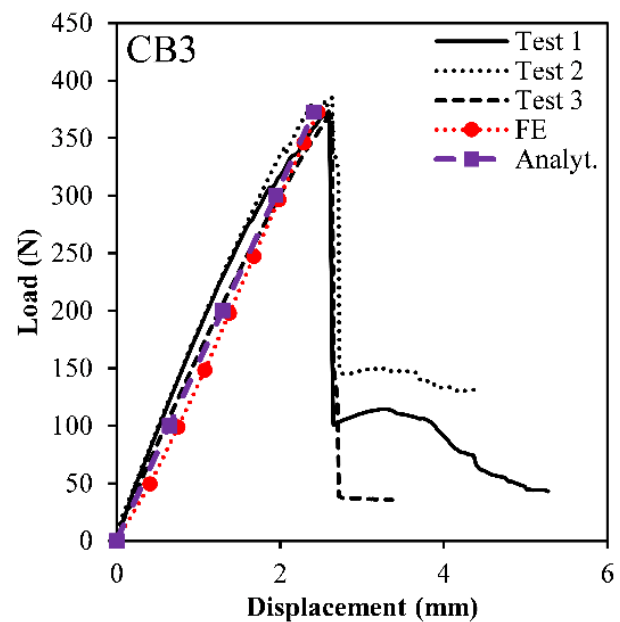

Fig. 7. The comparison of the load-displacement curves for CB3

Fig. 8 demonstrates damage analyses for this present study. For $\mathrm{CB} 1$ and $\mathrm{CB} 2$, a slight reduction in loading after reaching maximum loading was observed. This reduction was occurred due to the cracks formed in the first glass mat layer. With the first damage occurring and displacement continues to increase, interlaminar cracks (delamination) damages gradually occur between the glass mat and glass roving layers. Glass mat layers with different fiber configuration (multidirectional) started to be damaged before glass roving layers. As the increase in displacement continues, intralaminar cracks began to form between the glass roving layers. With the formation of fiber breakages starting in the first glass roving layer under ongoing loading conditions, sudden drops in the load were observed. After this drop in the load, the result damage occurred as a result of similar damages gradually occurring in other layers. 
On the other hand, $\mathrm{CB} 3$ which is different from $\mathrm{CB} 1$ and CB2 suddenly failed at averagely at $361 \mathrm{kN}$ due to matrix cracks in the fiber direction of $90^{\circ}$ (glass roving). Due to the direction of the extraction of this specimen, the fiber orientations in the glass roving layer were not able to carry the load since they were parallel to the applied load. In this specimen, the load carriage was carried out through glass mat layers. The glass roving layer behaved like a filling material; therefore, it caused a low load carrying capacity.
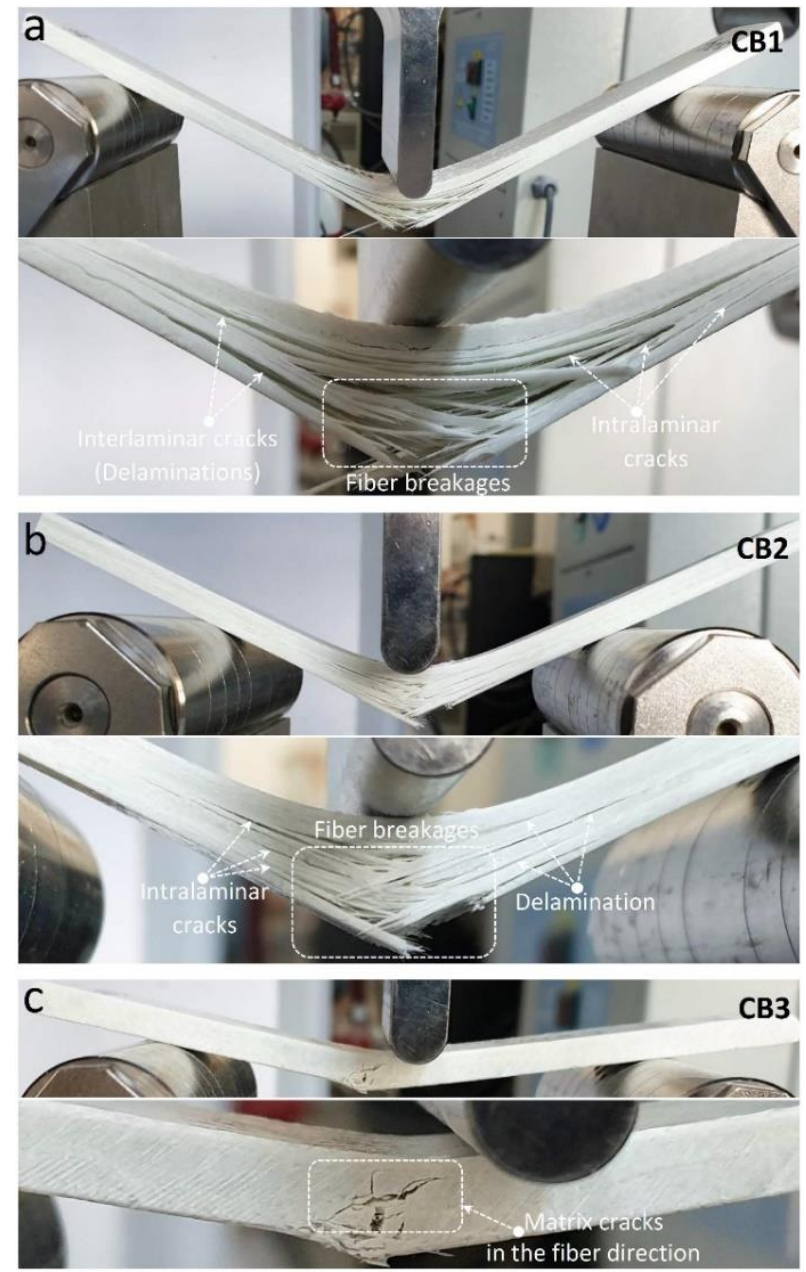

Fig. 8. Damages occurred during the experiments

\section{CONCLUSION}

This paper presents a classical laminated plate theory to solve bending deflection and stress. The presented analytical study was verified with the experimental study as well as numerical study. The comparisons of these studies revealed that the presented theoretical study can be used successfully to predict bending deflection and stress. The numerical results were also compared with the results obtained with the experiments and ABAQUS simulation results, and the results were found to be very similar.

The results of the study by Madenci et. al. [23] were very close to the results in this article. A simpler solution method was used in this study by using basic equations instead of the complex solution used in [23] article. No mechanical model was used in analytical calculations and the values obtained from the experimental results were used. Thanks to the common use of experimental and analytical work, there is no need for complex equation solutions.

In the $\mathrm{CB} 1$ and $\mathrm{CB} 2$ specimens, the glass roving and glass mat layers moved together and reached an average load capacity of $464 \mathrm{kN}$ and $448 \mathrm{kN}$, respectively. Unlike the other specimens, only the glass mat layer carried a load and reached an average load capacity of $361 \mathrm{kN}$ in specimen CB3. While damage development was observed in the CB1 and CB2 specimens as interlaminar (delamination) and intralaminar cracks damage modes, in the CB3 specimen, the initiation of the damage was observed in the glass roving layer in the form of dense matrix cracks in the direction of fiber.

\section{REFERENCES}

[1] S. Satasivam, Y. Bai, and X.-L. Zhao, "Adhesively bonded modular GFRP web-flange sandwich for building floor construction", Composite Structures, vol. 111, pp. 381392, 2014.

[2] J.R. Correia, F.A. Branco, and J.G. Ferreira, "Flexural behaviour of GFRP-concrete hybrid beams with interconnection slip", Composite Structures, vol. 77, pp. 6678, 2007.

[3] J.R. Correia, F.A. Branco, and J.G. Ferreira, "Flexural behaviour of multi-span GFRP-concrete hybrid beams", Engineering Structures, vol. 31, pp. 1369-1381, 2009.

[4] F. Aydın, A. Sarıbıyı, M. Sarıbıyı, and M. Ipek, "Experimental Study of Flexural Performance of Reinforced Concrete Beams and Hybrid Beams", Acta Physica Polonica A, vol. 134(1) pp. 244-247, 2018

[5] M. Saribiyik, and P. D. Gosling, "Experimental study of a bonded plastic fiber reinforced polymer connector assembly", Journal of Composites for Construction, vol. 8(6), pp. 549-559, 2004.

[6] A. Vedernikov, A. Safonov, F. Tucci, P. Carlone, and I. Akhatov, "Pultruded materials and structures: A review", Journal of Composite Materials, In Press, 2020.

[7] M. Saribiyik, "Design of light-weight structure by pultruded glass reinforced plastic", Journal of the Faculty of Engineering and Architecture of Gazi University, vol. 22(1), pp.199-205, 2007.

[8] M. Sarıbıyı, A. Cumhur, F. Aydın, and A. Sarıbıyık, "Pultruzyon Metodu İle Üretilen Cam Fiber Takviyeli Plastik Profillerin Sera Modellemesinde Kullanılması", International Symposium On Advances In Earthquake \& Structural Engineering, pp. 674-682, Antalya, Turkey, October 24-26 2007.

[9] G. Boscato and S. Ientile, "Experimental and numerical investigation on dynamic properties of thin-walled GFRP buckled columns", Composite Structures, vol. 189, pp. 273285, 2018.

[10] Bedford, URL: http://bedfordreinforced.com (Visited on Feb. 15, 2020) 
[11] M. Sarıbıyık, F. Aydin, N. Cağlar, and A. Sarıbıyık, "Use of the Pultruded Glass Reinforced Plastic in the Modelling of Earthquake Resistant Structure", In 8th International Congress on Advances in Civil Engineering, Eastern Mediterranean University, Famagusta, North Cyprus, pp. 15-17, 2008.

[12] M. Bell, D. Fick, R. Ament, and N.M. Lister, "The Use of Fiber-Reinforced Polymers in Wildlife Crossing Infrastructure", Sustainability, vol. 12(4), pp. 1557, 2020.

[13] J. Arbaoui, M. Tarfaoui, and A. El Malki Alaoui, "Dynamical characterisation and damage mechanisms of Eglass/vinylester woven composites at high strain rates compression", Journal of Composite Materials, vol. 50, pp. 3313-3323, 2016.

[14] E. Madenci, "A refined functional and mixed formulation to static analyses of fgm beams", Structural Engineering and Mechanics, vol. 69, pp. 427-437, 2019.

[15] A. Özütok and E. Madenci, "Static analysis of laminated composite beams based on higher-order shear deformation theory by using mixed-type finite element method", International Journal of Mechanical Sciences, vol. 130, pp. 234-243, 2017.

[16] L. Gemi, C. Aksoylu, Ş. Yazman, Y.O. Özkılıç, and M.H. Arslan, "Experimental investigation of shear capacity and damage analysis of thinned end prefabricated concrete purlins strengthened by CFRP composite", Composite Structures, p. 111399, 2019.

[17] V. Kahya, S. Karaca, F.Y. Okur, A.C. Altunışık, and M. Aslan, "Free vibrations of laminated composite beams with multiple edge cracks: Numerical model and experimental validation", International Journal of Mechanical Sciences, vol. 159, pp. 30-42, 2019.

[18] L. Almeida-Fernandes, N. Silvestre, and J.R. Correia, "Characterization of transverse fracture properties of pultruded GFRP material in tension", Composites Part B: Engineering, vol. 175, p. 107095, 2019.

[19] C. Wang, "Test on pultruded GFRP I-section under web crippling", Composites Part B: Engineering, vol. 77, pp. 27-37, 2015

[20] H. Xin, A.S. Mosallam, Y. Liu, C. Wang, and J. He, "Experimental and numerical investigation on assessing local bearing behavior of a pultruded GFRP bridge deck", Composite Structures, vol. 204, pp. 712-730, 2018.

[21] A. Saribiyik and M. Saribiyik, "Design of permanent greenhouse structure by pultruded glass reinforced plastic", Scientific Research and Essays, vol. 6, pp. 3629-3637, 2011.

[22] A. Saribiyik and N. Caglar, "Flexural strengthening of RC beams with low-strength concrete using GFRP and CFRP", Structural Engineering and Mechanics, vol. 58, pp. $825-845,2016$.

[23] E. Madenci, Y.O. Özkılıç, and L. Gemi, "Experimental and Theoretical Investigation on Flexure Performance of Pultruded GFRP Composite Beams with Damage Analyses", Composite Structures, vol. 242, pp. $112162,2020$.

[24] J. N. Reddy, Mechanics of laminated composite plates and shells: theory and analysis: CRC press, 2004.
[25] J. N. Reddy, "Energy principles and variational methods in applied mechanics", John Wiley \& Sons, 2002.

[26] Y.O. Özkılıç, E. Madenci, and L. Gemi, "Tensile and compressive behaviors of the pultruded GFRP lamina", Turkish Journal of Engineering (TUJE), vol. 4, pp. 169-175, 2020.

[27] Y.O. Özkılıç, "A new replaceable fuse for moment resisting frames: Replaceable bolted reduced beam section connections", Steel and Composite Structures, vol. 35(3), pp. 353-370, 2020.

[28] L. Gemi, "Investigation of the effect of stacking sequence on low velocity impact response and damage formation in hybrid composite pipes under internal pressure. A comparative study", Composites Part B: Engineering, vol. 153, pp. 217-232, 2018.

[29] L. Gemi, Ö.S. Şahin, and A. Akdemir, "Experimental investigation of fatigue damage formation of hybrid pipes subjected to impact loading under internal prestress", Composites Part B: Engineering, vol. 119, pp. 196205, 2017.

[30] L. Gemi, M. Kayrıcı, M. Uludağ, D.S. Gemi and Ö.S. Şahin, "Experimental and statistical analysis of low velocity impact response of filament wound composite pipes”, Composites Part B: Engineering, vol. 149, pp. 38-48, 2018.

[31] L. Gemi, U. Köklü, Ş. Yazman and S. Morkavuk, "The effects of stacking sequence on drilling machinability of filament wound hybrid composite pipes: Part-1 mechanical characterization and drilling tests", Composites Part B: Engineering, vol. 186, pp. 107787, 2020.

[32] L. Gemi, S. Morkavuk, U. Köklü and Ş. Yazman, "The effects of stacking sequence on drilling machinability of filament wound hybrid composite pipes: Part-1 damage analysis and surface quality", Composite Structures, vol. 235, pp. 111737, 2020.

[33] C. Aksoylu, Ş. Yazman, Y.O. Özkılıç, L. Gemi and M.H. Arslan, "Experimental analysis of reinforced concrete shear deficient beams with circular web openings strengthened by CFRP composite", Composite Structures, vol. 249, pp. 112561, 2020.

[34] L. Gemi, E. Madenci and Y.O. Özkılıç, "Çelik, Cam FRP ve Hibrit Donatılı Betonarme Kirişlerin Eğilme Performansının İncelenmesi", Düzce Üniversitesi Bilim ve Teknoloji Dergisi, vol. 8(2), pp. 1470-1483, 2020.

[35] E. Madenci, L. Gemi and Y.O. Özkılıç, "An Investigation on Flexure Behavior of Pultruded Glass Fiber Reinforced Polymer Composite Beams", 1st International Symposium on Innovations in Civil Engineering and Technology, pp. 379-384, 23-25 October, Afyon, Turkey, 2019.

[36] E. Madenci, Y.O. Özkılıç and L. Gemi, "The Effects of Length to Depth Ratio on the Reinforced Concrete Pultruded GFRP Beams", 1st International Symposium on Innovations in Civil Engineering and Technology, pp. 386391, 23-25 October, Afyon, Turkey, 2019.

[37] Y.O. Özkılıç, E. Madenci and L. Gemi, "Performance of Pultruded Glass Fiber Reinforced Polymer Composite Beams under Quasistatic Load”, 5th International 
Conference on Engineering Science, pp. 207-2212, 19 September, Ankara, Turkey, 2019.

[38] Y.O. Özkılıç, L. Gemi and E. Madenci. "Hybrid Reinforced Concrete Filled Pultruded GFRP Beams Strengthened by GFRP Composites", 5th International Conference on Engineering Science, pp. 213-217, 19 September, Ankara, Turkey, 2019.

[39] L. Gemi, E. Madenci and Y.O. Özkılıç, "Investigation of Reinforced Concrete-Filled Pultruded Beams Strengthened By GFRP Composite", The International Aluminium-Themed Engineering and Natural Sciences Conference, pp. 313-316, October 4-6, Seydişehir, Turkey, 2019.

[40] L. Gemi, Y.O. Özkılıç and E. Madenci. "An Experimental Investigation on Buckling Behavior of the Pultruded GFRP Beam", The International AlumınıumThemed Engineering and Natural Sciences Conference, pp. 306-308, 4-6 October, Seydişehir, Turkey, 2019.

[41] A. Saribiyik, B. Abodan, and M.T. Balci, "Experimental study on shear strengthening of RC beams with basalt FRP strips using different wrapping methods", Engineering Science and Technology, an International Journal, In Press, 2020.
[42] A. Castellano, A. Fraddosio, S. Marzano, and M.D. Piccioni, "Some advancements in the ultrasonic evaluation of initial stress states by the analysis of the acoustoelastic effect", Procedia Engineering vol. 199, pp. 1519-1526, 2017. [43] L. Gemi, and M.A. Köroğlu, "Çekme bölgesi lifli beton olan cam fiber takviyeli polimer (GFRP) ve çelik donatılı etriyesiz kirişlerin eğilme etkisi altındaki davranışı ve hasar analizi", Selçuk Üniversitesi Mühendislik, Bilim ve Teknoloji Dergisi, vol. 6, pp. 654-667, 2018.

[44] L. Gemi, M.A. Köroğlu, and A. Ashour, "Experimental study on compressive behavior and failure analysis of composite concrete confined by glass/epoxy $\pm 55^{\circ}$ filament wound pipes", Composite Structures, vol. 187, pp. 157-168, 2018.

[45] A. Castellano, P. Foti, A. Fraddosio, U. Galietti, S. Marzano, and M.D. Piccioni, "Characterization of Material Damage by Ultrasonic Immersion Test", Procedia Engineering, vol. 109, pp. 395-402, 2015.

[46] E. Madenci, Y.O. Özkılıç, L. Gemi, "Buckling and free vibration analyses of pultruded GFRP laminated composites: Experimental, numerical and analytical investigations", Composite Structures, vol. 254, pp. 112806, 2020 . 